\title{
Glucagon-like peptide-1 and the exenatide analogue AC3174 improve cardiac function, cardiac remodeling, and survival in rats with chronic heart failure
}

Que Liu ${ }^{1,2}$, Christen Anderson ${ }^{1,3}$, Anatoly Broyde ${ }^{1}$, Clara Polizzi ${ }^{1}$, Rayne Fernandez ${ }^{1}$, Alain Baron ${ }^{1}$, David G Parkes ${ }^{1 *}$

\begin{abstract}
Background: Accumulating evidence suggests glucagon-like peptide-1 (GLP-1) exerts cardioprotective effects in animal models of myocardial infarction (MI). We hypothesized that chronic treatment with GLP-1 or the exenatide analog AC3174 would improve cardiac function, cardiac remodeling, insulin sensitivity, and exercise capacity (EC) in rats with MI-induced chronic heart failure (CHF) caused by coronary artery ligation.

Methods: Two weeks post-Ml, male Sprague-Dawley rats were treated with GLP-1 (2.5 or 25 pmol/kg/min), AC3174 (1.7 or $5 \mathrm{pmol} / \mathrm{kg} / \mathrm{min}$ ) or vehicle via subcutaneous infusion for 11 weeks. Cardiac function and morphology were assessed by echocardiography during treatment. Metabolic, hemodynamic, exercise-capacity, and body composition measurements were made at study end.

Results: Compared with vehicle-treated rats with CHF, GLP-1 or AC3174 significantly improved cardiac function, including left ventricular (LV) ejection fraction, and end diastolic pressure. Cardiac dimensions also improved as evidenced by reduced LV end diastolic and systolic volumes and reduced left atrial volume. Vehicle-treated CHF rats exhibited fasting hyperglycemia and hyperinsulinemia. In contrast, GLP-1 or AC3174 normalized fasting plasma insulin and glucose levels. GLP-1 or AC3174 also significantly reduced body fat and fluid mass and improved exercise capacity and respiratory efficiency. Four of 16 vehicle control CHF rats died during the study compared with 1 of 44 rats treated with GLP-1 or AC3174. The cellular mechanism by which GLP-1 or AC3174 exert cardioprotective effects appears unrelated to changes in GLUT1 or GLUT4 translocation or expression.

Conclusions: Chronic treatment with either GLP-1 or AC3174 showed promising cardioprotective effects in a rat model of CHF. Hence, GLP-1 receptor agonists may represent a novel approach for the treatment of patients with CHF or cardiovascular disease associated with type 2 diabetes.
\end{abstract}

\section{Introduction}

Glucagon-like peptide-1 (7-36) (GLP-1) is an endogenous incretin hormone that modulates insulin-mediated effects on glucose uptake and metabolism [1-3]. GLP-1 receptors are found in the heart, and several lines of evidence suggest GLP-1 may have cardioprotective benefits [4]. Therapeutic use of GLP-1 is limited by its rapid degradation by dipeptidyl peptidase-4 (DPP-4). Exenatide, a synthetic version of the 39 -amino acid peptide

\footnotetext{
* Correspondence: dparkes@amylin.com

'Amylin Pharmaceuticals Inc., San Diego, CA, USA 92121

Full list of author information is available at the end of the article
}

exendin-4 not susceptible to cleavage by DPP-4, was originally isolated from the salivary secretions of the Gila monster lizard and shares several glucoregulatory properties with GLP-1 [5,6]. AC3174 ([Leu $\left.{ }^{14}\right]$ exendin-4) is an analog of exenatide with a single amino acid substitution that has similar glucoregulatory properties to both GLP-1 and exenatide [7]. Accumulating evidence from both animal and human studies suggests GLP-1 receptor agonists can improve insulin sensitivity and activate c-AMP mediated signaling pathways in cardiac muscle cells [8-11]. 
Several studies have demonstrated a strong association of whole-body insulin resistance with chronic heart failure (CHF) [12,13], suggesting an important role of insulin resistance and/or altered glucose homeostasis in the pathophysiology of CHF. Since the failing heart utilizes glucose rather than free fatty acids as an energy source $[14,15]$, treatment with GLP-1 or exenatide may improve both cardiac glucose metabolism and cardiac function in CHF [16]. Additionally, acute treatment with GLP-1 or exenatide has shown cardioprotective effects in several animal models of ischemia and perfusion injury [16-20], and recent data has reported that exenatide significantly reduces intimal hyperplasia in insulin resistant animals independent of exenatide-associated weight loss [21]. Further, in pilot studies continuous infusion of GLP-1 improved cardiac function in patients with myocardial infarction (MI), improved left ventricular (LV) function in patients with CHF, and was beneficial in patients with type 2 diabetes with CHF [22-24]. However, no response was observed with acute GLP-1 infusion in patients with established cardiac disease [25].

The purpose of the present study was to determine whether chronic treatment with GLP-1 or the exenatide analog AC3174 has cardioprotective effects in a rat model of MI-induced CHF, to identify specific aspects of cardiac and metabolic function affected by GLP-1 or AC3174, and to evaluate some potential mechanisms for any observed effects.

\section{Materials and methods Induction of myocardial infarction}

All experiments were performed in accordance with the protocols and guidelines approved by the Institutional Animal Care Committee and the NIH guide for the Care and Use of Laboratory Animals. MI was induced in male Sprague-Dawley rats (200-225 g) by the supplier (Charles River Laboratories, Wilmington, MA) using a previously described procedure [26]. Briefly, the left anterior descending coronary artery was ligated with a silk suture after an incision in the fourth intercostal space under anesthesia (2\% Isoflurane). The same surgical procedure was also performed on a group of rats (sham-operated) except that the suture around the coronary artery was not ligated. The wound was then closed with metal clips, and the rats were allowed to recover for one week before being shipped. Two weeks after MI, rats with an LV infarct size between $20 \%$ and $45 \%$, as estimated by echocardiograph at the authors' facility, based on LV chamber kinetic movement [27]. These rats were then randomly assigned to treatment groups and alzet pumps were implanted. Randomized rats were infused subcutaneously with $2.5 \mathrm{pmol} / \mathrm{kg} / \mathrm{min}$ GLP-1 (GLPL, $\mathrm{n}=11), 25 \mathrm{pmol} / \mathrm{kg} / \mathrm{min}$ GLP-1 (GLPH, $\mathrm{n}=12), 1.7 \mathrm{pmol} / \mathrm{kg} / \mathrm{min}$ AC3174 (3174L, $\mathrm{n}=13)$,
$5 \mathrm{pmol} / \mathrm{kg} / \mathrm{min}$ AC3174 $(3174 \mathrm{H}, \mathrm{n}=7)$, or vehicle $(25 \%$ $\mathrm{DMSO}+75 \% \mathrm{H}_{2} \mathrm{O}$, control $\mathrm{n}=13-16$, sham $\mathrm{n}=10$ ) via osmotic Alzet pumps (Durect Corp, Cupertino, CA) for 11 weeks. AC3174 and GLP-1 doses were selected to provide equivalent plasma exposure [28]. Echocardiography was performed at $0,1,5,7$, and 11 weeks of treatment $(2,3,7,9$, and 13 weeks post-MI). At 10 weeks of treatment (12 weeks post-MI), MI rats were subjected to a treadmill test. During the last week of treatment, blood samples for fasting plasma insulin and glucose levels were collected before terminal hemodynamic measurements were recorded.

\section{Echocardiography}

Echocardiograms were recorded under light anesthesia (50 mg/kg ketamine hydrochloride plus $10 \mathrm{mg} / \mathrm{kg}$ xylazine intraperitoneally) using a Hewlett-Packard 5500 system equipped with $\mathrm{S} 12(5-12 \mathrm{MHz})$ phased-array and L15 (7-15 MHz) linear transducers. Transthoracic Doppler echocardiography was performed as previously described [29]. Briefly, short-axis images were obtained at the papillary muscle level and $2 \mathrm{D}$ guided M-mode tracings were recorded at a speed of $150 \mathrm{~mm} / \mathrm{s}$. Anterior and posterior end-diastolic wall thickness and LV internal dimensions were measured and \% fractional shortening (FS\%) was calculated. Left atrial (LA) volume, LV end-diastolic volume (LVEDV), LV end-systolic volume (LVESV), LV ejection fraction (LVEF), LV end-diastolic dimension (LVEDD), and LV end-systolic dimension (LVESD) were measured and calculated from apical views [30,31].

Pulsed-wave Doppler spectra of mitral inflow were obtained from the apical 4-chamber view. The peak velocities of early (E) and late (A) filling waves, and $E$ wave deceleration rate were measured. LV diastolic filling was assessed by E/A ratio. Compliance was assessed by $\mathrm{E}$ wave deceleration rate. Aortic velocity time integral (VTI) and LV outflow track diameter were determined, then stroke volume (SV) and cardiac output $(\mathrm{CO})$ were calculated according to the formula: $\mathrm{CO}=$ Aortic VTI $\times$ $\left[\pi(\mathrm{LV} \text { outflow diameter } / 2)^{2}\right] \times$ heart rate [32]. Images were digitally acquired and stored for offline analysis by a trained sonographer blinded to the study groups.

\section{Exercise performance}

Immediately before the treadmill test at 12 weeks postMI (10 weeks of treatment), baseline plasma lactate levels were measured via tail vein puncture in conscious rats fasted for 5 hours. At the time of the treadmill test, 2 rats were simultaneously placed on a 2-track treadmill (Columbus Instruments, Columbus, $\mathrm{OH}$ ) at a constant $5 \%$ grade enclosed by a metabolic chamber (Oxymax Deluxe, Columbus Instruments) through which airflow was maintained at a constant flow rate. Basal 
measurements were recorded over a period of 8 to 10 minutes. The treadmill was then started at a velocity of $8 \mathrm{~m} / \mathrm{min}$ for 3 minutes, followed by $12 \mathrm{~m} / \mathrm{min}$ for 3 minutes, and then maintained at $18 \mathrm{~m} / \mathrm{min}$ until rats reached exhaustion. The endpoint for the treadmill test was determined by a rat's inability to maintain the pace of the treadmill and remain on the electric shock grid for over 6 seconds. Exercise capacity (EC) was calculated as $\mathrm{EC}(\mathrm{kgm})=$ body weight $(\mathrm{kg}) \times$ degree of grade $\times$ running distance. Oxygen consumption $\left(\mathrm{VO}_{2}\right)$ was measured as described [32]. Plasma lactate was again measured one minute after the treadmill test.

\section{Hemodynamics}

Hemodynamic measurements were obtained under anesthesia (2\% isofluorane) at 13 weeks post-MI (11 weeks of treatment). A 2F micromanometer-tipped transducer (Millar Instruments, Houston, TX) connected to a PowerLab (8/30) system (ADInstruments, Colorado Springs, CO) was inserted into the right carotid artery to record systolic and diastolic blood pressure. The pressure transducer was then advanced into the LV to measure LV systolic (LVSP) and end-diastolic (LVEDP) pressures, the first derivative of LV pressure over time $( \pm \mathrm{dp} / \mathrm{dt})$ and heart rate $(\mathrm{HR})$.

\section{Biochemical determinations}

Plasma glucose and insulin levels were monitored after an overnight fast at 13 weeks post-MI. Blood samples $(20 \mu \mathrm{l})$ were collected from a tail vein. Glucose and insulin were measured using an Elite glucometer (Bay, Elkhart, Indiana) and Ultrasensitive rat insulin ELISA kit (Crystal Chem Inc, Chicago, Illinois), respectively. Baseline fasting plasma insulin and glucose were utilized to calculate the homeostasis model assessment (HOMA) of insulin sensitivity. The estimate of insulin resistance from the HOMA score was calculated as described by Matthews et al [33].

\section{Body composition analysis and histopathological examination}

Body weights of conscious rats were monitored weekly. After completion of hemodynamic measurements, rats were deeply anesthetized with $5 \%$ isoflurane. Lean and fat mass were measured by quantitative magnetic resonance (QMR) (EchoMRI; Echo Medical System, Huston, TX) as described by Tinsley et al [34]. After QMR measurement, rats were sacrificed under anesthesia and hearts were excised. The atria were trimmed from the ventricles, then the right ventricle, left ventricle, and lung were separated and weighed. LV tissues were immersion-fixed in 10\% buffered formalin. Each heart was cut in cross section at four levels from apex to base and prepared for routine histological analysis. The infarct portion of the LV was measured as previously described [35].

\section{Immunoblot analysis}

Cardiac ventricular tissue of post-MI CHF rats from control, GLPH and $3174 \mathrm{H}$ treated groups were homogenized in lysis buffer and homogenized tissue extracts were run on Bio Criterion XT Precast Gels and transferred to PVDF membranes (all from BioRad, Hercules, CA). The membrane was immunoblotted with antibodies directed against AKT2, cardiac sarcoplasmic reticulum $\mathrm{Ca}^{2+}$ ATPase (SERCA2), eNOS, glucose transporters (GLUT 1 and GLUT 4), GAPDH, or PI3kinase-beta, and an HRP conjugate for the secondary antibody (all antibodies from Abcam, Cambridge, MA). Membranes were developed using SuperSignal West Dura Substrate (Pierce, Rockford, IL), and assessed on an Alpha Imager using chemifluorescence. AlphaEase FC software version 1.4.0 was used for quantification. Results were obtained in integrated density value units per $10 \mu \mathrm{g}$ total protein.

Purified plasma membranes (PM) and cytosolic (Cyt) fractions were prepared using density gradient centrifugation as previously described [36]. Translocation of GLUT-1 and GLUT-4 was analyzed by assessing the protein contents in the PM preparations expressed as percentage of total protein expression in the PM and Cyt fractions [37].

\section{Statistics}

Two-way repeated measures ANOVA followed by Bonferroni multiple comparison tests were used to test group differences in LV function and remodeling over time. When a significant interaction was found ( $\mathrm{p}$ $<0.05$ ), differences between groups were analyzed for each time point. Treadmill test data, body composition, western blot, and hemodynamic measurements were analyzed by one-way ANOVA followed by Bonferroni multiple comparison or nonparametric Kruskal-Wallis test followed by Dunnett's multiple comparison. Withingroup comparisons of baseline and Peak $\mathrm{VO}_{2}$, lactate and glucose data were analyzed by Student's paired $t$ test. Time to death due to CHF was evaluated using Kaplan-Meier survival curves. A log-rank trend test for both GLP-1 and AC3174 was performed to evaluate dose-response trend between control, low, and high doses. The trend analysis was performed using equallyspaced weights with no adjustment made for multiple comparisons. Results are shown as mean \pm SEM.

\section{Results}

\section{General characteristics of rats with CHF}

Post-MI vehicle control rats showed evidence of $\mathrm{CHF}$, including the development of LV dilatation, and LV 
Table 1 Echocardiographic data in post-MI rats

\begin{tabular}{|c|c|c|c|c|c|c|c|}
\hline & Timepoint & $\begin{array}{l}\text { Sham Operated } \\
\qquad(\mathrm{N}=10)\end{array}$ & $\begin{array}{l}\text { Vehicle Control } \\
\quad(N=13)\end{array}$ & $\begin{array}{c}\text { GLPL } \\
(N=11)\end{array}$ & $\begin{array}{c}\text { GLPH } \\
(\mathrm{N}=11)\end{array}$ & $\begin{array}{c}3174 \mathrm{~L} \\
(\mathrm{~N}=11)\end{array}$ & $\begin{array}{l}3174 \mathrm{H} \\
(\mathrm{N}=7)\end{array}$ \\
\hline \multirow[t]{2}{*}{ LVEDD (cm) } & Baseline & $0.63 \pm 0.01$ & $0.93 \pm 0.02^{*}$ & $0.89 \pm 0.01^{*}$ & $0.88 \pm 0.02^{*}$ & $0.86 \pm 0.02^{*}$ & $0.85 \pm 0.04^{*}$ \\
\hline & End of Study & $0.82 \pm 0.01 \dagger$ & $1.16 \pm 0.02$ & $1.04 \pm 0.03 \dagger$ & $1.03 \pm 0.03 \dagger$ & $1.07 \pm 0.03 \dagger$ & $0.98 \pm 0.05+$ \\
\hline \multirow[t]{2}{*}{ LVESD (cm) } & Baseline & $0.34 \pm 0.01$ & $0.77 \pm 0.02^{*}$ & $0.73 \pm 0.02^{*}$ & $0.71 \pm 0.02^{*}$ & $0.70 \pm 0.03^{*}$ & $0.70 \pm 0.03^{*}$ \\
\hline & End of Study & $0.05 \pm 0.01 \dagger$ & $0.99 \pm 0.03$ & $0.85 \pm 0.03 \dagger$ & $0.82 \pm 0.04 \dagger$ & $0.89 \pm 0.04$ & $0.73 \pm 0.06+$ \\
\hline \multirow[t]{2}{*}{ FS (\%) } & Baseline & $46 \pm 2$ & $17 \pm 1^{*}$ & $18 \pm 1^{*}$ & $19 \pm 1^{*}$ & $18 \pm 2^{*}$ & $18 \pm 1^{*}$ \\
\hline & End of Study & $39 \pm 1+$ & $16 \pm 1$ & $20 \pm 2$ & $21 \pm 2+$ & $18 \pm 1 \dagger$ & $26 \pm 3+$ \\
\hline \multirow[t]{2}{*}{ LVEDV (ml) } & Baseline & $0.26 \pm 0.02$ & $0.59 \pm 0.03^{*}$ & $0.52 \pm 0.03^{*}$ & $0.53 \pm 0.03^{*}$ & $0.56 \pm 0.04^{*}$ & $0.52 \pm 0.05^{*}$ \\
\hline & End of Study & $0.51 \pm 0.02 \dagger$ & $0.99 \pm 0.05$ & $0.83 \pm 0.05 \dagger$ & $0.72 \pm 0.04 \dagger$ & $0.77 \pm 0.02 \dagger$ & $0.73 \pm 0.06+$ \\
\hline \multirow[t]{2}{*}{ LVESV (ml) } & Baseline & $0.08 \pm 0.01$ & $0.37 \pm 0.03^{*}$ & $0.32 \pm 0.02^{*}$ & $0.33 \pm 0.03^{*}$ & $0.34 \pm 0.03^{*}$ & $0.33 \pm 0.04^{*}$ \\
\hline & End of Study & $0.17 \pm 0.01 \dagger$ & $0.69 \pm 0.04$ & $0.52 \pm 0.05 \dagger$ & $0.42 \pm 0.04 \dagger$ & $0.47 \pm 0.03 \dagger$ & $0.44 \pm 0.07 \dagger$ \\
\hline \multirow[t]{2}{*}{ LVEF (\%) } & Baseline & $69 \pm 2$ & $37 \pm 2^{*}$ & $39 \pm 1^{*}$ & $39 \pm 2^{*}$ & $39 \pm 3^{*}$ & $38 \pm 3^{*}$ \\
\hline & End of Study & $66 \pm 2+$ & $31 \pm 2$ & $38 \pm 3+$ & $43 \pm 3+$ & $39 \pm 3+$ & $41 \pm 5+$ \\
\hline E Wave $(\mathrm{cm} / \mathrm{s})$ & End of Study & $0.89 \pm 0.04$ & $1.05 \pm 0.50$ & $0.93 \pm 0.07$ & $0.89 \pm 0.05$ & $1.02 \pm 0.06$ & $0.95 \pm 0.04$ \\
\hline A Wave $(\mathrm{cm} / \mathrm{s})$ & End of Study & $0.48 \pm 0.06 \dagger$ & $0.36 \pm 0.06$ & $0.42 \pm 0.04 \dagger$ & $0.43 \pm 0.04 \dagger$ & $0.45 \pm 0.05 t$ & $0.44 \pm 0.05 \dagger$ \\
\hline \multirow[t]{2}{*}{ E/A Ratio } & Baseline & $1.6 \pm 0.1$ & $3.4 \pm 0.5^{*}$ & $4.4 \pm 0.8^{*}$ & $3.9 \pm 0.6^{*}$ & $3.9 \pm 0.8^{*}$ & $4.0 \pm 0.4^{*}$ \\
\hline & End of Study & $2.0 \pm 0.2+$ & $4.5 \pm 0.8$ & $2.5 \pm 0.4 \dagger$ & $2.5 \pm 0.4 \dagger$ & $2.9 \pm 0.6 \dagger$ & $2.5 \pm 0.5+$ \\
\hline \multirow[t]{2}{*}{ E Wave Deceleration $\left(\mathrm{m} / \mathrm{s}^{2}\right)$} & Baseline & $13.8 \pm 0.6$ & $18.5 \pm 1.2^{*}$ & $19.2 \pm 1.8^{*}$ & $17.7 \pm 0.8^{*}$ & $17.9 \pm 1.4^{*}$ & $18.0 \pm 0.6^{*}$ \\
\hline & End of Study & $16 \pm 1+$ & $25 \pm 3$ & $18 \pm 3+$ & $16 \pm 2 \dagger$ & $19 \pm 3$ & $17 \pm 2+$ \\
\hline \multirow[t]{2}{*}{ LV Wall Thinning Ratio } & Baseline & $1.06 \pm 0.02$ & $0.87 \pm 0.02^{*}$ & $0.89 \pm 0.03^{*}$ & $0.89 \pm 0.02^{*}$ & $0.89 \pm 0.03^{*}$ & $0.88 \pm 0.03^{*}$ \\
\hline & End of Study & $1.08 \pm 0.03 \dagger$ & $0.76 \pm 0.02$ & $0.84 \pm 0.04$ & $0.88 \pm 0.04 \dagger$ & $0.79 \pm 0.04$ & $0.93 \pm 0.06+$ \\
\hline \multirow[t]{2}{*}{ Heart Rate (beats/min) } & Baseline & $273 \pm 5$ & $270 \pm 7$ & $266 \pm 10$ & $292 \pm 10$ & $284 \pm 7$ & $261 \pm 2$ \\
\hline & End of Study & $257 \pm 15$ & $243 \pm 7$ & $269 \pm 8$ & $262 \pm 6$ & $246 \pm 9$ & $258 \pm 7$ \\
\hline CO/Body Wt (ml/min/g) & End of Study & $0.21 \pm 0.01 \dagger$ & $0.17 \pm 0.01$ & $0.20 \pm 0.01 \dagger$ & $0.20 \pm 0.01 \dagger$ & $0.19 \pm 0.01 \dagger$ & $0.22 \pm 0.01 \dagger$ \\
\hline
\end{tabular}

systolic and diastolic dysfunction (Table 1; Figure 1). Echocardiographic studies showed progressive differences in LV geometry between vehicle control (infarcted) and sham-operated rats. Post-MI rats had significant LV dilatation 2 weeks after ligation. During the following 11 weeks, there was continued LV chamber enlargement in the vehicle control group. The prominent increase in cavity dimensions in the infarcted hearts resulted in a significant decrease in relative wall thickness (anterior wall/posterior wall thickness) compared with vehicle control rats [31]. Hemodynamic abnormalities were characteristic of rats with CHF. Specifically, vehicle control rats showed significantly depressed LV $\pm \mathrm{dp} / \mathrm{dt}$ and elevated LVEDP (Table 2), while cardiac output/body weight was decreased by $19 \%$ ( $\mathrm{p}<0.01)$ compared with sham-operated rats at 13 weeks post-MI. Control rats at 13 weeks post-MI exhibited hyperglycemia and insulin resistance compared with vehicle sham animals (Figure 2). Thus, the post-MI rats we studied represented a homogenous group with characteristics predisposing them to pathologic LV remodeling and $\mathrm{CHF}$.

\section{Echocardiographic characteristics of infarcted rat hearts prior to treatment}

In all randomized post-MI rats at baseline, LV systolic function (LVEF, CO/B.W, FS\%) was depressed and LV chamber size (LVESD, LVEDD, LVESV and LVEDV) increased compared with sham-operated rats (Figure 1; Table 1). LV diastolic dysfunction was present in postMI rats, as assessed by pulse-wave Doppler recordings of mitral flow, compared with sham-operated rats. Increased $\mathrm{E} / \mathrm{A}$ ratio and $\mathrm{E}$ wave deceleration rate, characteristics of LV diastolic dysfunction in failing hearts, was observed in all randomized MI rats compared with sham-operated rats. Left atrial volume was also increased (Figure 1). Prior to treatment with a GLP-1R agonist, there were no significant differences in LV or LA chamber size, or systolic or diastolic function among the randomized post-MI rats. 

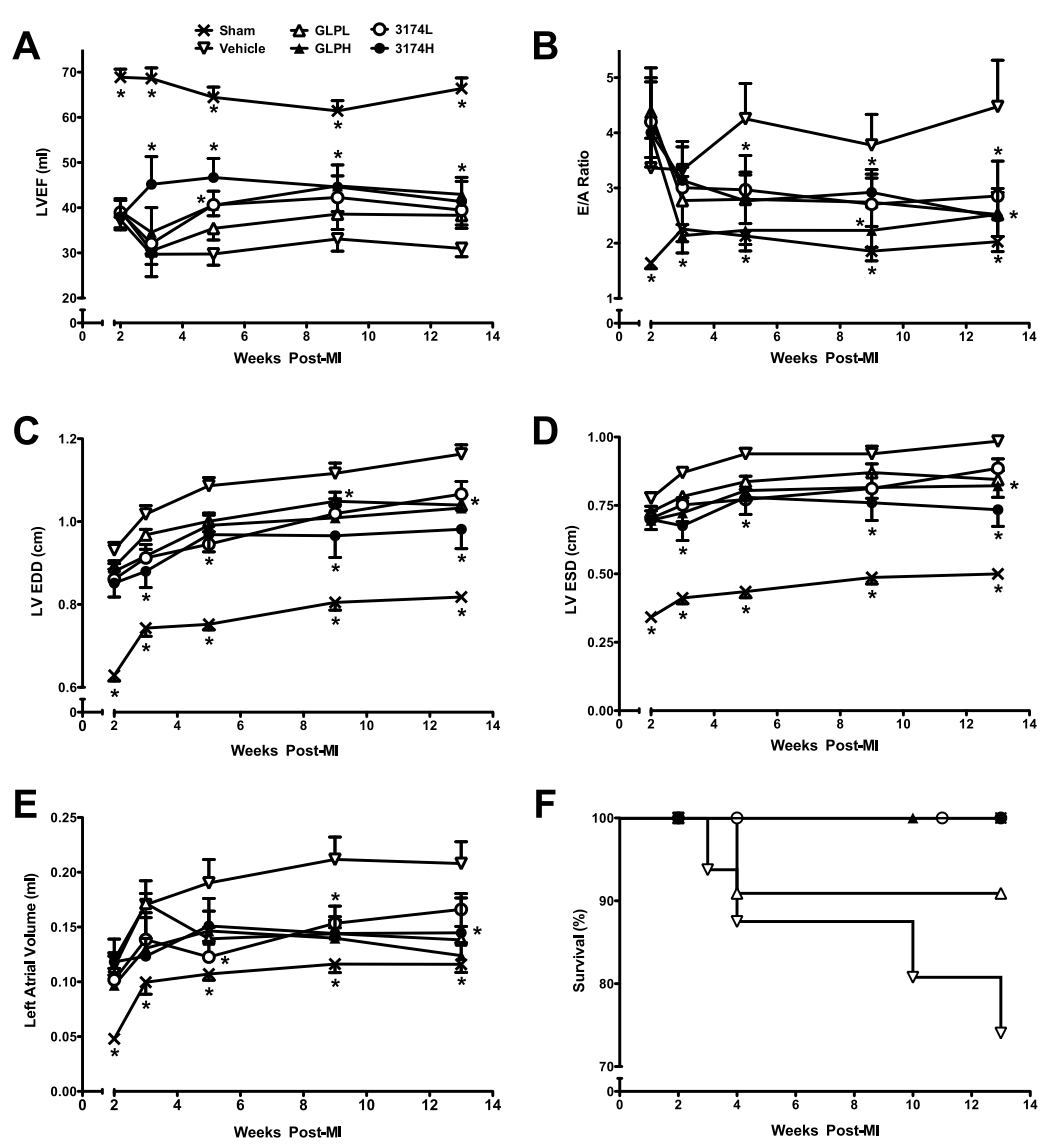

Figure 1 Effect of chronic treatment with GLP-1 or AC3174 on cardiac function and survival. (A) Left ventricular ejection fraction (LVEF). At weeks 3 and 5 post-MI, 3174H LVEF was significantly less than GLPL LVEF $(p<0.05)$. At week 3 post-Ml, 3174H LVEF was significantly less than 3174L LVEF ( $p<0.05)$. (B) Doppler ratio for early (E) to late (A) transmitral flow velocity (E/A ratio). (C) Left ventricular end-diastolic dimension (LVEDD). (D) Left ventricular end-systolic dimension (LVESD). (E) Left atrial volume. (F) Kaplan-Meier survival curves. The number of chronic heart failure (CHF) related deaths (from 2 weeks post-MI) and the total number in each group were sham 0/10; control 4/16; GLPL 1/12; GLPH 0/12; $3174 \mathrm{~L} \mathrm{0/13}$ and $3174 \mathrm{H} \mathrm{0/7.}{ }^{*} p<0.05$ versus vehicle-treated control group.

\section{Hemodynamic and cardiac function after 11 weeks of treatment}

\section{Control rats}

During the 11-week observation period, LV systolic and diastolic function progressively decreased in control rats compared with sham-operated rats (Figure 1, Tables 1, 2 ). Specifically, in the vehicle control rats at 13 weeks
post-MI, LVEF decreased 53\% ( $\mathrm{P}<0.05)$, FS\% decreased $60 \%(\mathrm{P}<0.05), \mathrm{E} / \mathrm{A}$ ratio increased $120 \%(\mathrm{P}<0.05)$, and LVEDP increased by $97 \%(\mathrm{p}<0.05)$ compared with the sham-operated rats.

Treated rats

Treatment with GLP-1 and AC3174 significantly improved both diastolic function (E/A ratio, LVEDP,

Table 2 Hemodynamic changes at the end of the study

\begin{tabular}{|c|c|c|c|c|c|c|}
\hline & $\begin{array}{l}\text { Sham Operated } \\
\quad(N=10)\end{array}$ & $\begin{array}{l}\text { Vehicle Control } \\
\quad(N=12)\end{array}$ & $\begin{array}{c}\text { GLPL } \\
(N=11)\end{array}$ & $\begin{array}{c}\text { GLPH } \\
(\mathrm{N}=12)\end{array}$ & $\begin{array}{c}3174 \mathrm{~L} \\
(\mathrm{~N}=13)\end{array}$ & $\begin{array}{l}3174 \mathrm{H} \\
(\mathrm{N}=7)\end{array}$ \\
\hline Heart Rate (beats/min) & $252 \pm 13$ & $268 \pm 21$ & $294 \pm 20$ & $295 \pm 13$ & $256 \pm 16$ & $312 \pm 15$ \\
\hline Mean BP (mmHg) & $83 \pm 5$ & $80 \pm 8$ & $87 \pm 7$ & $84 \pm 4$ & $72 \pm 2$ & $83 \pm 4$ \\
\hline LVEDP $(\mathrm{mmHg})$ & $10.6 \pm 0.9^{*}$ & $20.9 \pm 1.4$ & $12.7 \pm 0.01^{*}$ & $12.3 \pm 1.6^{*}$ & $14.4 \pm 1.4^{*}$ & $13.9 \pm 1.7^{*}$ \\
\hline$+\mathrm{dp} / \mathrm{dt}(\mathrm{mmHg} / \mathrm{s})$ & $5789 \pm 430^{*}$ & $4426 \pm 541$ & $6157 \pm 654^{*}$ & $6044 \pm 284^{*}$ & $5234 \pm 372$ & $5948 \pm 488^{*}$ \\
\hline$-\mathrm{dp} / \mathrm{dt}(\mathrm{mmHg} / \mathrm{s})$ & $5826 \pm 655^{*}$ & $3731 \pm 564$ & $5450 \pm 652^{*}$ & $5582 \pm 465^{*}$ & $4424 \pm 386$ & $5798 \pm 592^{*}$ \\
\hline
\end{tabular}

Mean \pm SEM. ${ }^{*} \mathrm{P}<0.05$ versus vehicle-treated group. BP, blood pressure; $\mathrm{dp} / \mathrm{dt}$, first derivative of left ventricular pressure over time. 

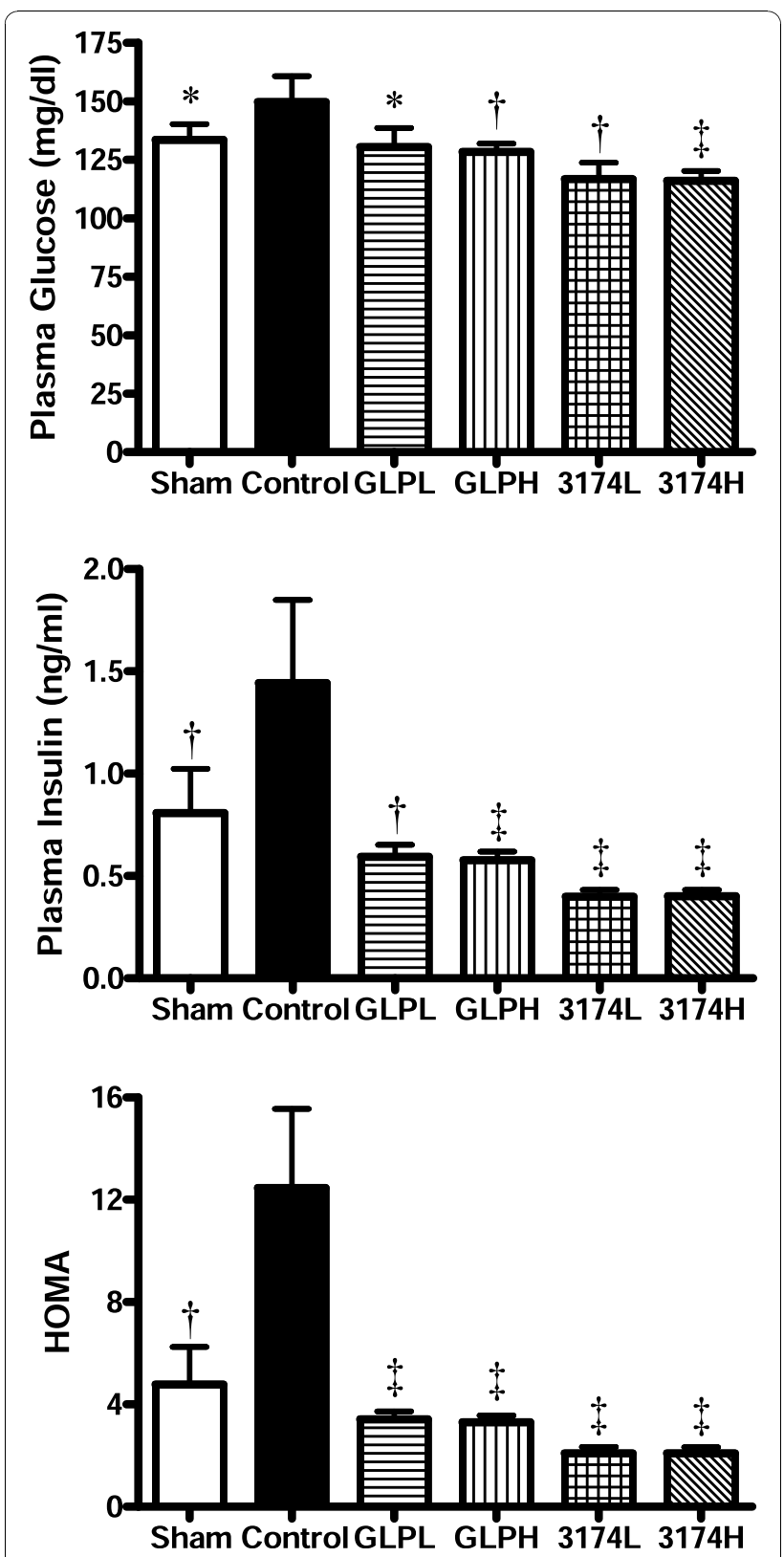

Figure 2 Effects of GLP-1 and AC3174 on fasting glucose, insulin levels and HOMA 13 weeks post-MI. ${ }^{*} p<0.05,+p<$ $0.01, \neq p<0.001$ versus vehicle control group. Results are mean + SEM.

E wave deceleration rate) and systolic function (LVEF, $\mathrm{FS} \%, \mathrm{CO} / \mathrm{BW}$ ) compared with the vehicle control group over time, although cardiac function did not reach that of sham-operated animals for most parameters (Figure 1, Tables 1, 2). Specifically, LVEDP was significantly reduced by $41 \%$ in the GLPH group and $33 \%$ in the $3174 \mathrm{H}$ group compared with the vehicle control group. Conversely, LVEF was significantly increased by $39 \%$ in the GLPH group and $33 \%$ in the $3174 \mathrm{H}$ group. In the GLPH and $3174 \mathrm{H}$ groups,
LV contractility $( \pm \mathrm{dp} / \mathrm{dt})$ was also significantly improved $(\mathrm{P}<0.05)$, while $\mathrm{HR}$ and BP were not affected.

\section{Cardiac geometry Control rats}

LV chamber size in the vehicle control group increased progressively compared with sham-operated rats during the 11-week observation period, while LV wall thickness ratio was significantly reduced $(\mathrm{P}<0.05$, Figure 1 , Tables 1 and 2). LVEDD was significantly increased by $42 \%$, LVESD was significantly increased by $97 \%$, LVEDV was significantly increased by $95 \%$, and LVESV were significantly increased by $300 \%$ in vehicle control postMI rats 13 weeks post-MI. In vehicle control rats, LV wall thickness ratio was reduced by $30 \%$ and LA volume was increased by $79 \%$ compared with sham-operated rats 13 weeks post MI.

\section{Treated rats}

The progression of LV chamber dilatation and thinning of the LV wall was dose-dependently attenuated in both GLP-1 and AC3174 treatment groups (Figure 1, Tables 1 and 2). Compared with the vehicle control group, LVEDV was significantly reduced by $26 \%(\mathrm{P}<0.05)$ and LVESV was significantly reduced by $36 \%(\mathrm{P}<0.05)$ in the $3174 \mathrm{H}$ group. LVEDV was significantly reduced by $27 \%(\mathrm{P}<0.05)$ and LVESV was significantly reduced by $39 \%(\mathrm{P}<0.05)$ in the GLPH group. Treatment with GLP-1 or AC3174 dose-dependently attenuated the increase of LA volume observed in the vehicle control rats.

\section{Insulin sensitivity Control rats}

Fasting plasma glucose and insulin levels were significantly higher in the vehicle control group compared with the sham-operated group at 13 weeks post-MI ( $\mathrm{P}<$ 0.05 , Figure 2). As a result, insulin resistance as assessed by HOMA, was 2 fold higher than in the sham-operated group.

\section{Treated rats}

After 11 weeks of treatment, GLP-1 or AC3174 significantly reduced plasma glucose, insulin and HOMA compared with the vehicle-treated/control group ( $\mathrm{P}<$ 0.05 , Figure 2 ), indicating that insulin sensitivity was improved in all treated groups.

\section{Treadmill test, Peak $\mathrm{VO}_{2}$, and plasma lactate levels Control rats}

Basal $\mathrm{VO}_{2}$ was comparable, and peak $\mathrm{VO}_{2}\left(\mathrm{PVO}_{2}\right)$ was significantly higher than basal $\mathrm{VO}_{2}$ among all groups $(\mathrm{P}<0.05$, Table 3). Compared with sham-operated rats, running distance was significantly decreased by $63 \%$ $(\mathrm{P}<0.05)$ and EC was significantly decreased by $63 \%$ $(\mathrm{P}<0.05)$ in vehicle treated post-MI rats with CHF. 
Table 3 Metabolic response during the treadmill test at the end of the study

\begin{tabular}{|c|c|c|c|c|c|c|c|}
\hline & & $\begin{array}{l}\text { Sham Operated } \\
\quad(N=10)\end{array}$ & $\begin{array}{l}\text { Vehicle Control } \\
\quad(N=12)\end{array}$ & $\begin{array}{c}\text { GLPL } \\
(\mathrm{N}=11)\end{array}$ & $\begin{array}{c}\text { GLPH } \\
(\mathrm{N}=12)\end{array}$ & $\begin{array}{c}3174 \mathrm{~L} \\
(\mathrm{~N}=13)\end{array}$ & $\begin{array}{l}3174 \mathrm{H} \\
(\mathrm{N}=7)\end{array}$ \\
\hline \multirow[t]{2}{*}{ Plasma Lactate (mM) } & Basal & $1.7 \pm 0.2^{*}$ & $2.7 \pm 0.2$ & $1.9 \pm 0.2^{*}$ & $1.9 \pm 0.2^{*}$ & $2.0 \pm 0.2^{*}$ & $2.1 \pm 0.1^{*}$ \\
\hline & Peak & $2.5 \pm 0.2 \dagger$ & $3.1 \pm 0.4$ & $2.7 \pm 0.3 \dagger$ & $3.1 \pm 0.6+$ & $3.7 \pm 0.5 \dagger$ & $3.2 \pm 0.5 \dagger$ \\
\hline \multirow[t]{2}{*}{$\mathrm{VO}_{2}(\mathrm{ml} / \mathrm{kg} / \mathrm{h})$} & Basal & $949 \pm 67$ & $1027 \pm 84$ & $1040 \pm 110$ & $1117 \pm 108$ & $1073 \pm 77$ & $872 \pm 57$ \\
\hline & Peak & $2022 \pm 155 t$ & $1949 \pm 290 \dagger$ & $2334 \pm 311 \dagger$ & $2659 \pm 329+$ & $2554 \pm 307 \dagger$ & $1431 \pm 155 † \#$ \\
\hline $\mathrm{EC}\left(\mathbf{k g}^{*} \mathrm{~m}\right)$ & & $679 \pm 127^{*}$ & $253 \pm 52$ & $452 \pm 58^{*}$ & $547 \pm 56^{*}$ & $535 \pm 89^{*}$ & $562 \pm 167^{*}$ \\
\hline EC/Peak Lactate Ratio & & $290 \pm 54^{*}$ & $86 \pm 18$ & $200 \pm 36^{*}$ & $234 \pm 44^{*}$ & $163 \pm 31^{*}$ & $203 \pm 69^{*}$ \\
\hline EC/Peak $\mathrm{VO}_{2}$ Ratio & & $38.0 \pm 7.2^{*}$ & $14.0 \pm 3.2$ & $23.4 \pm 4.2$ & $24.8 \pm 4.3^{*}$ & $24.4 \pm 5.4$ & $40.4 \pm 12.2^{*}$ \\
\hline Running Distance (m) & & $266 \pm 50^{*}$ & $99 \pm 21$ & $177 \pm 22$ & $212 \pm 21^{*}$ & $220 \pm 36^{*}$ & $251 \pm 82^{*}$ \\
\hline
\end{tabular}

Mean \pm SEM. ${ }^{*} \mathrm{P}<0.05$ versus vehicle-treated group. $\mathrm{TP}<0.05$ peak versus basal in same group. \#P $<0.053174 \mathrm{~L}$ versus $3174 \mathrm{H}$ group. VO 2 , oxygen consumption; EC, exercise capacity.

\section{Treated rats}

Treatment with GLP-1 or AC3174 significantly improved running distance and $\mathrm{EC}$ in rats with $\mathrm{CHF}$ compared with vehicle control animals $(\mathrm{P}<0.05$, Table 3$)$. Compared with the vehicle control group, $\mathrm{PVO}_{2}$ was not significantly changed in sham-operated and GLP-1 or AC3174 treated groups. As a result, the $\mathrm{EC} / \mathrm{PVO}_{2}$ ratio was significantly higher in all groups compared with the vehicle control group $(\mathrm{P}<0.05)$. $\mathrm{PVO}_{2}$ in the $3174 \mathrm{H}$ group was significantly lower than in the $3174 \mathrm{~L}$ group $(\mathrm{P}$ $<0.05)$. Of note, the $\mathrm{EC} / \mathrm{PVO}_{2}$ ratio in the $3174 \mathrm{H}$ group was 1.9 fold-higher than the control group.

Immediately after exercise, peak plasma lactate level was significantly higher than basal levels in each group $(\mathrm{P}<0.05)$. Interestingly, basal plasma lactate levels in the vehicle control group were significantly higher than in the sham-operated and GLP-1 or AC3174-treated groups. Although peak plasma lactate levels were comparable among all groups, the EC/lactate ratio was significantly higher in sham-operated and GLP-1 or AC3174 treated groups $(\mathrm{P}<0.05)$, indicating a higher efficiency of glucose utilization.

\section{Survival}

Over the 13-week post-MI period, $25 \%$ of the vehicle control group (4 out of 16 rats) died with signs of CHF (e.g., respiratory distress, and general fatigue: defined as a fast respiratory rate and a reluctance to move.). Eight percent of the GLPL group (1 out of 12 rats) died with signs of CHF. There were no deaths in the sham-operated, GLPH, 3174L, or $3174 \mathrm{H}$ groups. As shown in Figure $1 \mathrm{~F}$, the Kaplan-Meier survival curves indicate increased mortality for the vehicle control MI group compared with the other treatment groups. Trend tests for GLP-1 ( $\mathrm{p}=0.05)$ and AC3174 ( $\mathrm{p}<0.05)$ showed marginally significant dose responses. There was no significant difference between the GLP-1 and AC3174 treatment groups. The death rate for all rats treated with a GLP-1R agonist was $2 \%$ (1 death out of 44 rats).

\section{Body composition, heart, lung weight and infarct size}

Progressive body weight loss was observed in the AC3174-treated groups during the 11-week treatment period. Weight loss was associated with a dose-dependent reduction in fat mass accompanied by preservation of lean body mass (Table 4 ). In the $3174 \mathrm{H}$ group, body weight decreased $17 \%$, fat mass decreased $45 \%$ and fluid mass decreased 11\% compared with the vehicle control group. By contrast, there were no significant changes in body weight and composition in the GLP-1 treatment groups over the same time period. LV, RV, and lung weights were generally significantly lower in sham, GLP1 and AC3174 groups compared with the vehicle control group $(\mathrm{P}<0.05)$. Because body weight also decreased in the GLP-1 and AC3174 groups, the ratios of LV, RV, and lung to body weight did not reach significance for all doses of GLP-1 and AC3174, although lung weight was reduced at the higher doses of both agents. There was no significant change in infarct size among any of the groups.

\section{Effects of GLP-1 or AC3174 on myocardial GLUT4 and GLUT1 translocation}

Figure 3A shows a representative immunoblot of the relative GLUT1 or GLUT4 distribution between the PM and Cyt fractions in sham, vehicle, GLP1 H or $3174 \mathrm{H}$ treated MI rats. Antibody binding specifically detected GLUT1 and GLUT4 protein of average molecular mass $\sim 50 \mathrm{kDa}$ and $\sim 45 \mathrm{kDa}$, respectively, matching the previously described molecular mass of these proteins [37]. Compared with the vehicle control group, treatment with GLP-1 or AC3174 did not change the relative GLUT4 content in the plasma membrane (60.0 $\pm 4.4 \%$ and $61.4 \pm 5.5 \%$ vs $55.3 \pm 4.9 \%$, respectively; Figure $3 \mathrm{~B}$ ). 
Table 4 Whole body and selected organ composition at the end of the study

\begin{tabular}{|c|c|c|c|c|c|c|}
\hline & $\begin{array}{l}\text { Sham Operated } \\
\quad(N=10)\end{array}$ & $\begin{array}{l}\text { Vehicle Control } \\
\quad(N=12)\end{array}$ & $\begin{array}{c}\text { GLPL } \\
(N=11)\end{array}$ & $\begin{array}{c}\text { GLPH } \\
(\mathrm{N}=12)\end{array}$ & $\begin{array}{c}3174 \mathrm{~L} \\
(N=13)\end{array}$ & $\begin{array}{l}3174 \mathrm{H} \\
(\mathrm{N}=7)\end{array}$ \\
\hline Body Wt (g) & $511 \pm 16$ & $522 \pm 17$ & $523 \pm 14$ & $518 \pm 12$ & $493 \pm 10$ & $435 \pm 15^{*}$ \\
\hline Baseline Body Wt (g) & $257 \pm 7$ & $272 \pm 8$ & $270 \pm 7$ & $276 \pm 10$ & $258 \pm 5$ & $258 \pm 5$ \\
\hline Fat Mass (g) & $58 \pm 6$ & $47 \pm 6$ & $45 \pm 6$ & $51 \pm 9$ & $33 \pm 3^{*}$ & $26 \pm 5^{*}$ \\
\hline Lean Mass ( $\mathrm{g}$ ) & $35 \pm 1$ & $38 \pm 1$ & $37 \pm 2$ & $35 \pm 2$ & $38 \pm 2$ & $34 \pm 1$ \\
\hline Fluid Mass (g) & $323 \pm 12$ & $343 \pm 9$ & $329 \pm 14$ & $331 \pm 15$ & $332 \pm 11$ & $305 \pm 9^{*}$ \\
\hline LV (g) & $1.07 \pm 0.06^{*}$ & $1.36 \pm 0.10$ & $1.26 \pm 0.05$ & $1.13 \pm 0.03^{*}$ & $1.13 \pm 0.05^{*}$ & $1.06 \pm 0.04^{*}$ \\
\hline RV (g) & $0.22 \pm 0.01^{*}$ & $0.28 \pm 0.02$ & $0.22 \pm 0.01^{*}$ & $0.23 \pm 0.01^{*}$ & $0.24 \pm 0.01^{*}$ & $0.20 \pm 0.02^{*}$ \\
\hline Lung (g) & $1.53 \pm 0.05^{*}$ & $2.45 \pm 0.05$ & $1.94 \pm 0.35$ & $1.66 \pm 0.13^{*}$ & $1.48 \pm 0.03^{*}$ & $1.51 \pm 0.07^{*}$ \\
\hline LV Wt/Body Wt (\%) & $0.21 \pm 0.01^{*}$ & $0.26 \pm 0.01$ & $0.24 \pm 0.01$ & $0.22 \pm 0.01^{*}$ & $0.23 \pm 0.01^{*}$ & $0.24 \pm 0.01$ \\
\hline RV Wt/Body Wt (\%) & $0.04 \pm 0.002^{*}$ & $0.05 \pm 0.01$ & $0.04 \pm 0.002^{*}$ & $0.04 \pm 0.002^{*}$ & $0.05 \pm 0.002$ & $0.05 \pm 0.002$ \\
\hline Lung Wt/Body Wt (\%) & $0.30 \pm 0.01^{*}$ & $0.48 \pm 0.10$ & $0.37 \pm 0.07$ & $0.32 \pm 0.02^{*}$ & $0.30 \pm 0.01^{*}$ & $0.33 \pm 0.01^{*}$ \\
\hline Infarct Size (\%) & $0 \pm 0$ & $33 \pm 4$ & $30 \pm 2$ & $29 \pm 2$ & $31 \pm 3$ & $31 \pm 6$ \\
\hline
\end{tabular}

Mean \pm SEM. ${ }^{*} \mathrm{P}<0.05$ versus vehicle-treated group. $\mathrm{Wt}$, weight; $\mathrm{LV}$, left ventricle; $\mathrm{RV}$, right ventricle.

Relative GLUT1 content on the plasma membrane was also unchanged by GLP-1 or AC3174 treatment (37.7 \pm $2.9 \%$ or $34.8 \pm 5.1 \%$ vs $41.8 \pm 2.5 \%)$. These results suggest that GLP-1 or AC3174 do not significantly affect myocardial GLUT1 and GLUT4 translocation under the present experimental conditions.
Effects of GLP-1 or AC3174 on cardiac protein expression Immunoblot analysis of cardiac tissue did not demonstrate any significant changes in expression of GLUT4, AKT2, SERCA2a or PI3Kbeta with GLP-1 or AC3174 treatment (Figure 4), although trends towards decreased GLUT1 and eNOS expression were noted.

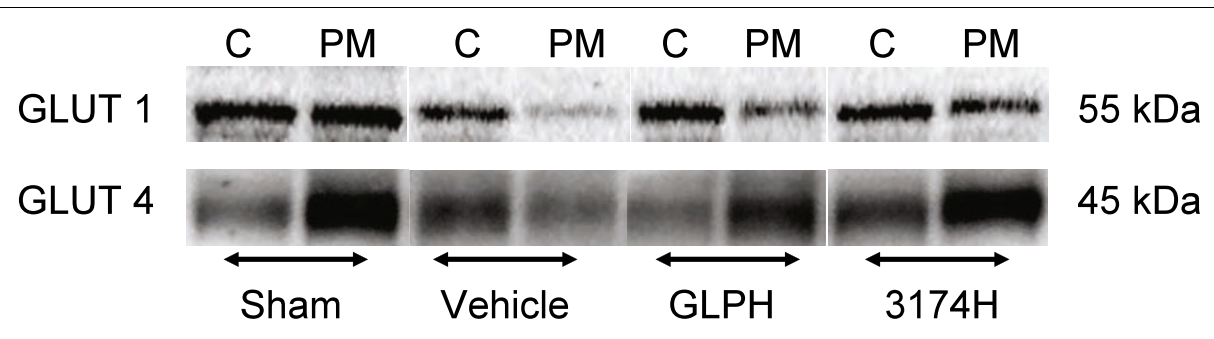

GLUT 4

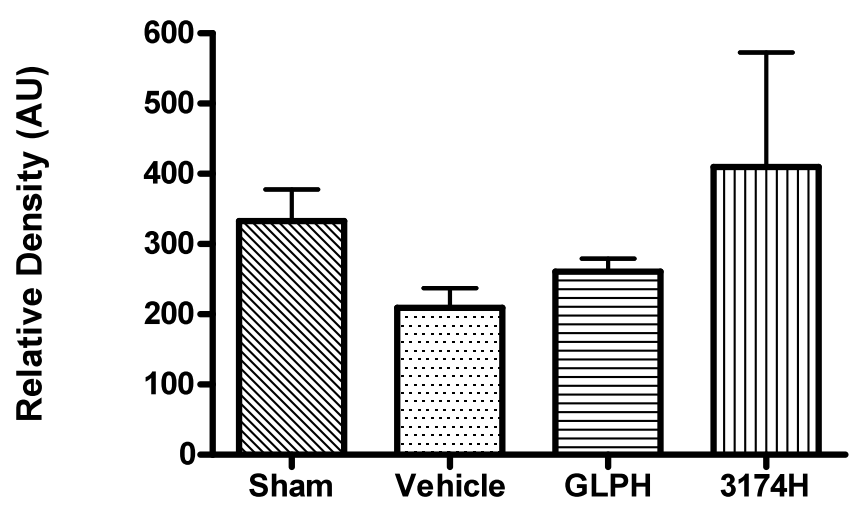

Figure 3 Effects of GLP-1 or AC3174 treatment on GLUT1 and GLUT4 translocation. MI rat hearts were obtained from the sham, vehicle control, GLPH and 3174H treatment groups. (A) Representative Western blots of GLUT1 and GLUT4 in plasma membrane and cytoplasm. (B) Quantitative analysis of GLUT4 proteins in plasma membrane. No significant changes with treatment compared to vehicle control were observed. Results are mean + SEM. $N=3$ per group. 


\section{Discussion}

\section{Overview}

The present study demonstrates that 11 weeks of GLP-1 or AC3174 infusion to post-MI rats developing CHF can significantly improve multiple clinically-relevant parameters of cardiac function in a model of moderate, stable, compensated heart failure. In comparison with vehicle-treated rats, improvements were observed in LVEF, fractional shortening, transmitral flow ratio, E-wave velocity, cardiac wall-thinning ratio, LVEDP, $\mathrm{dP} /$ $\mathrm{dT}$, and cardiac output. Measured parameters of cardiac morphology were also improved by GLP-1 or AC3174 infusion, including LV end systolic and end diastolic diameter, and left atrial volume. In contrast, heart rate and mean blood pressure in GLP-1R agonist-treated animals were not different from those of vehicle control animals. Left ventricular infarct size was not affected by GLP-1 or AC3174, and no differences in body weightadjusted measures of heart weight were observed. However, unadjusted LV and RV weights were decreased. Furthermore, a statistically significant improvement in survival was observed with GLP-1 and AC3174 treatments at both low and high doses.

More detailed analyses of the physiological changes resulting from either GLP-1 or AC3174 infusion indicate that fluid balance, glucose metabolism, and respiratory efficiency improved compared with vehicle control animals with CHF. Differences in fluid balance were evidenced by reductions in lung weight (adjusted for body weight) and fluid mass compared with post-MI vehicle control animals. Improvements in glucose metabolism were evidenced by reductions in plasma glucose, plasma insulin, and insulin resistance. Improved exercise capacity in GLP-1 or AC3174-treated animals was associated with reduced peak oxygen consumption during exercise and lower basal lactate production, reflecting improved respiratory efficiency. Running distances in post-MI rats treated with GLP-1 or AC3174 were not significantly different from that of sham-operated animals and were double that of vehicle control animals with CHF.

\section{Exploration of Possible Mechanisms}

These studies did not identify the molecular mechanisms mediating the GLP-1 and AC3174 changes in physiological function. No differences in translocation of GLUT1 or GLUT4 to the plasma membrane were observed between GLP-1 and AC3174-treated rats and no statistically significant differences in expression of these proteins were identified. This contrasts with the results from chronically infarcted Wistar rat hearts where myocardial GLUT4 protein levels were 28\% lower in infarcted hearts than in sham-operated hearts, and insulin-stimulated glucose uptake was $42 \%$ lower [38]. No differences in the protein expression of AKT2,
SERCA2a, or PI3Kbeta were observed, and the observed trend towards reduction in eNOS expression might be expected to diminish cardiac function rather than improve it. However, studies in normal primary human coronary artery endothelial cells in vitro have demonstrated a similar lack of overt exenatide effect on eNOS and AKT2 protein expression on a background of enhanced activation of both proteins [39]. Indeed, endothelial cells had a substantial proliferative response to exenatide treatment and this response was mediated by activation of both the AKT2/eNOS and the PKA/ PI3K signal transduction pathways. Furthermore, activation of the GLP-1 receptor was required upstream for stimulation of these pathways. Along the same lines of inquiry, treatment of diabetic post-MI mice with the DPP-4 inhibitor sitagliptin, which augments concentrations of endogenous full-length GLP-1, reduced mortality and improved cardiac function [40].

\section{Role of Glucose Metabolism in CVD}

This study demonstrated the development of insulin resistance and hyperglycemia in a MI-induced rat model of CHF, supporting the similarity of this model system with human $\mathrm{CHF}$. Improvements in whole-body insulin sensitivity and glycemic control are closely associated with attenuation of cardiac insulin resistance and appear to protect the heart in both patients and animals with coronary heart disease [14,41]. Several animal studies have shown that increasing glucose utilization not only improves cardiac function, but also attenuates cardiac remodeling during CHF $[14,35,42]$. Further, a role of GLP-1 in cardioprotection is supported by the cardiac phenotype of GLP-1R knockout mice where resting heart rate is reduced, LV wall thickness is increased, and LVEDP is elevated compare with wild-type mice [43]. Although baseline hemodynamics are normal, after the administration of insulin or epinephrine LV contractility and diastolic function also show impairment.

The close relationship between the metabolic syndrome and cardiovascular diseases, including $\mathrm{CHF}$, is well established $[4,11-13,20,25,38]$. In previous studies, exenatide progressively reduced body weight in obese animals and humans, and increased insulin sensitivity in obese animals [6,44-47]. In the present study, the combined actions of the exenatide analog AC3174 to reduce body weight, fat mass, insulin resistance, cardiac remodeling, and improve glycemic control and cardiac function suggest the overall improvement in metabolic status observed with AC3174 treatment may contribute to its cardioprotective mechanisms. Further evidence was provided by the decreased rates of mortality in AC3174-treated MI rats compared with vehicle control rats. In patients with $\mathrm{CHF}$ and diabetes, but not in normoglycemic patients with CHF, a 5 week infusion of 


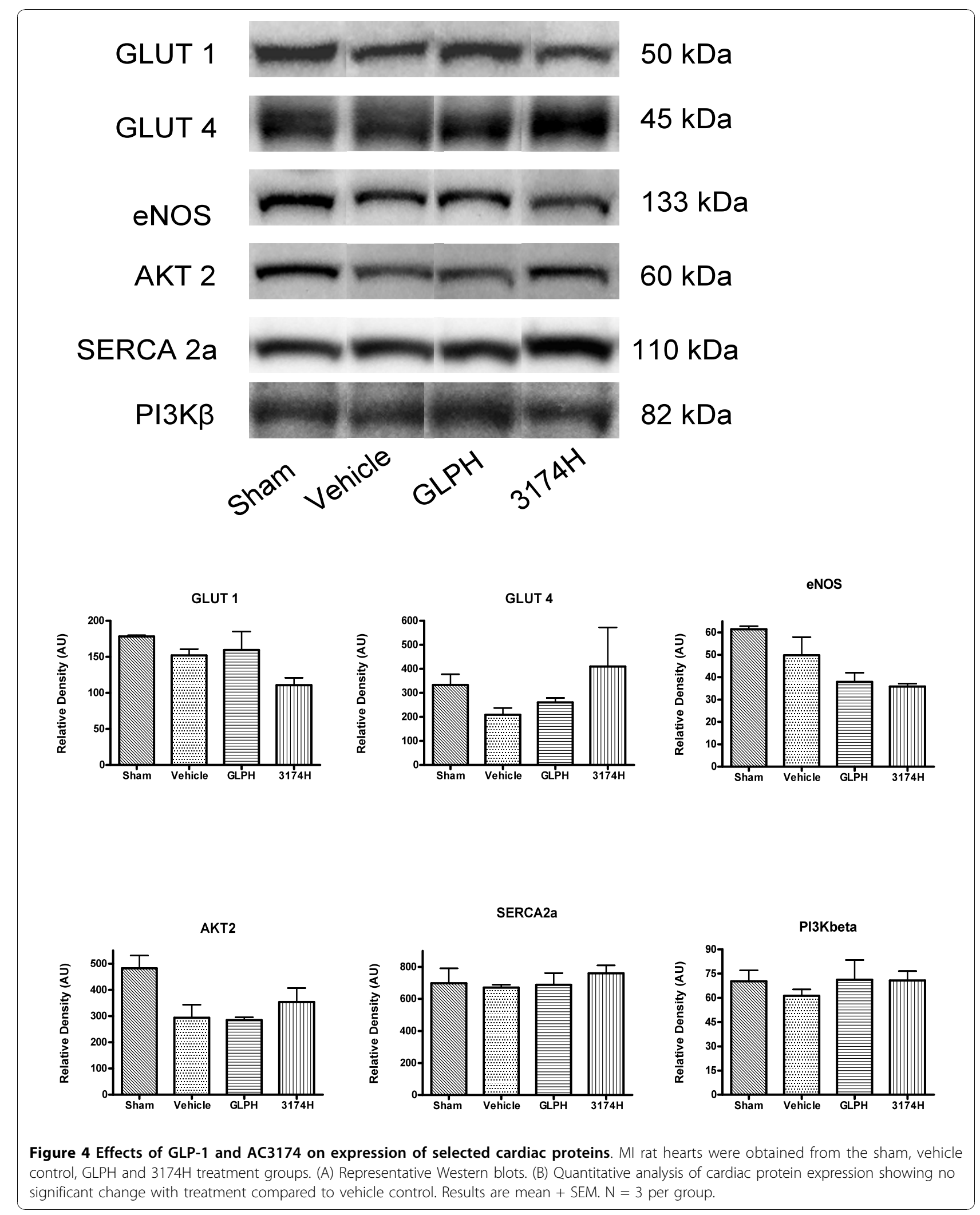


GLP-1 significantly reduced plasma glucose levels [23]. However, cardiac function in both groups of patients was significantly and comparably improved by GLP-1. These results suggest that GLP-1 effects that are independent of whole body metabolic improvements contribute relatively more to GLP-1's cardioprotective effects, perhaps via direct myocardial actions.

In a global ischemia model in isolated rat hearts, GLP-1 treatment post-MI exhibited only a small tendency to increase mechanical (inotropic) performance [48]. Rather, GLP-1's primary mechanism of action was cardioprotective in nature (39\% reduction in infarct size) and mediated through the GLP-1 receptor. In isolated mouse hearts, GLP-1 increased functional recovery and cardiomyocyte viability after ischemia-reperfusion injury [49]. In models of MI (ischemia with or without reperfusion) and heart failure, treatment with GLP-1 or exenatide treatment has generally been associated with improvements in postischemia cardiac function or infarct size. The most striking results were observed in studies with longer follow-up times. For example, in pigs treated for 2 days, exenatide reduced infarct area 33\%, prevented deterioration of systolic and diastolic cardiac function, and decreased myocardial stiffness $54 \%$ when assessed on the third day after treatment initiation [19]. At the molecular level, AKT activation increased in concert with increased expression of anti-apoptotic BCL-2 and decreased expression of proapoptotic caspase 3 . In a second example, 7 days of preMI treatment with the GLP-1R agonist liraglutide reduced mouse cardiac infarct size, while improving cardiac output and survival [9]. Four weeks post-MI, measures of systolic function (cardiac output, stroke volume) and mitral flow velocities (E/A ratio) were significantly improved compared with sham-operated mice, combined with reduced LV dilatation. Furthermore, all these effects were independent of liraglutide-induced weight loss. Ex vivo, liraglutide prevented ischemia-reperfusion injury in isolated, perfused mouse hearts and reduced apoptosis in neonatal mouse cardiomyocytes. In normal healthy mice (without MI), liraglutide increased AKT activation, a response that was absent in GLP-1R knockout mice. In the one study examining human patients with acute MI, 72-hours of GLP-1 infusion added to standard therapy was associated with significantly improved LVEF (29\% to 39\% compared with no change in the control group) and contractile function $(-21 \%$ in regional wall motion score index versus no change in the control group) measured 6 to 12 hours after infusion [22]. Moreover, in pigs and dogs GLP-1 improved myocardial glucose-uptake and metabolism $[50,51]$.

\section{Clinical Evidence}

The ability of exenatide to reduce blood pressure in humans may contribute to the peptide's potential to play a cardioprotective role. In an open-label, 82-week study in patients with type 2 diabetes, exenatide reduced mean diastolic blood pressure and improved lipid profiles [44]. In a 24-week, clinical trial in patients with type 2 diabetes, exenatide reduced mean systolic and diastolic blood pressure in contrast to non-significant changes in the placebo arm [47]. The blood pressure effects of exenatide treatment lasting at least 6 months was also examined in pooled data from 6 trials including 2,171 subjects [52]. Exenatide was associated with significantly decreased systolic BP compared with placebo or insulin in patients with elevated BP at baseline, with the greatest effects observed in subjects with baseline systolic $\mathrm{BP} \geq 130 \mathrm{mmHg}$.

In another study, 12 weeks of exenatide treatment in patients with type 2 diabetes was associated with a trend towards lower 24-hr, daytime, and nighttime systolic blood pressure, but had no clinically meaningful effect on heart rate, compared with placebo [53]. Further, using a well-established risk-assessment model, Sullivan et al. [54] projected substantial reductions in cardiovascular death rates and fewer cardiovascular events over 30 years in patients with diabetes treated with the GLP$1 \mathrm{R}$ agonist, liraglutide.

Exercise intolerance is a hallmark symptom of CHF regardless of disease etiology, and is closely related to increased insulin resistance [55]. Agents that stimulate glucose oxidation (directly or indirectly) improve exercise capacity in humans [56-58]. In the present study, a reduction in basal plasma lactate and an increase in the ratio of exercise capacity to the lactate peak during exercise was observed with GLP-1 or AC3174 treatment, in parallel with increased insulin sensitivity. These data suggest whole body glucose utilization was improved in all treatment groups. Thus, it is possible that normalization of hyperglycemia and improvement in insulin sensitivity may have contributed to the enhancement of exercise performance, in addition to the benefits of improved cardiac function and remodeling. However, whether or not the improvements in insulin sensitivity associated with chronic GLP-1 or AC3174 treatment directly contributed to the cardioprotective effects of these peptides remains to be determined. Regarding the significantly lower $\mathrm{VO}_{2}$ levels observed in the $3174 \mathrm{H}$ group, reduced food intake/body weight may have contributed to this result. Previous studies have shown that equivalent doses of exenatide lower food intake in diet induced obese rats [46]. However, the mechanism of action of AC3174 to change $\mathrm{VO}_{2}$ is not clear and is likely to be multifactorial.

\section{Implications of GLP-R Activation for Survival after MI}

Survival increased with GLP-1 or AC3174 treatment in the MI-induced CHF rat model. Although attenuation of insulin resistance by GLP-1 or AC3174 may 
contribute to this benefit, insulin-independent cardiac or extra-cardiac actions such as vasodilatation, renoprotection, and reduction of apoptosis [2,59-61] may have also contributed to the reduction in mortality. Of mention, insulin sensitizers such as peroxisome proliferatorsactivated receptor $\gamma$ (PPAR $\gamma$ ) activators (e.g., thiazolidinediones) have cardioprotective effects similar to GLP-1. However, PPAR $\gamma$ activators are contraindicated in $\mathrm{CHF}$ due to their propensity to increase the incidence of fluid retention and edema in humans [62], and increase mortality in rats with MI-induced CHF [63].

While the mechanisms of the observed cardioprotective effects remain unclear, several likely mechanisms were explored. In a previous study of isolated perfused rat hearts subjected to ischemia and reperfusion, acute treatment with high concentrations of GLP-1 enhanced recovery of cardiac function by improving myocardial glucose uptake and translocation of the glucose transporters, GLUT-1 and GLUT-4, during reperfusion [20]. Although the mechanism of translocation remains elusive, it appears the AKT-2 downstream signal transduction pathway contributes to the translocation of GLUT-4 [64]. In the present study, long term treatment with GLP-1 or AC3174 did not significantly alter myocardial GLUT1 or GLUT4 translocation. These data suggest the observed cardioprotective effects may occur, at least in part, independent of specific cardiac metabolic improvements.

While GLP-1 and the exenatide analogue AC3174 exhibit comparable binding potency at the GLP-1 receptor [7], in this study AC3174 exhibited several distinct pharmacodynamic actions compared with GLP-1. For instance, treatment with AC3174 resulted in significant weight loss mediated by selective loss of body fat. Furthermore, the highest dose of AC3174 tested was associated with a relatively low $\mathrm{PVO}_{2}$. This could be due to relatively more potent and sustained inhibitory effects of exenatide on food intake and energy expenditure than observed with GLP-1 [65]. However, the cardioprotective effects of the GLP-1R agonist liraglutide in a mouse MI model were found to be independent of weight reduction [9].

In an isolated rat heart model of MI, administration of GLP-1 during the first 15 minutes post-ischemia reperfusion reduced infarct size through a GLP-1 receptormediated pathway, but had no inotropic effects (mechanical performance) [48]. In contrast, administration of the primary GLP-1 metabolite GLP-1(9-36) had no effect on infarct size, but did have a strong negative inotropic effect. Because GLP-1(9-36) has little or no binding affinity for the known GLP-1R, these data suggest the involvement of GLP-1R-independent effects on cardiac function post-MI. A more recent exploration of this hypothesis found that isolated mouse hearts rapidly convert infused GLP-1 to GLP-1(9-36) [66]. After ischemia-reperfusion injury of isolated mouse hearts, administration of GLP-1(9-36) or exenatide improved functional recovery, reduced infarct size, improved cardiomyocyte viability, reduced lactate dehydrogenase release and decreased caspase- 3 activation. Counter to expectations, the cardioprotective actions of GLP-1 (9-36) were blocked by an antagonist of GLP-1R binding, yet preserved in cardiomyocytes from GLP-1R knockout mice. Overall, these data lend further support to a cardio-sparing signal transduction pathway distinct from that associated with the GLP-1 receptor.

\section{Limitations}

One possible limitation of this study is that standard treatments for MI, e.g. ACE-inhibitors, were not coadministered with GLP-1 or AC3174. However, in a recent publication [60], the ACE inhibitor captopril had additive effects with AC3174 in reducing cardiac left ventricular mass and improving renal morphology in a rat model of hypertension characterized by profound hypertension, cardiac hypertrophy, insulin resistance, renal pathology, and early-onset mortality. AC3174 plus captopril lengthened survival and had anti-hypertensive, insulin-sensitizing, and renoprotective effects. Another possible limitation is that levels of catecholamines, cortisol, glucagon, free fatty acids, renin, and aldosterone were not measured in the MI rat model. Levels of these compounds can increase in heart failure patients and it is possible similar changes may have influenced the physiological responses to AC3174 or GLP-1 in the rat model.

\section{Conclusions}

GLP-1 and the exenatide analog, AC3174, each independently demonstrated cardioprotective effects after longterm treatment in rats with MI-induced CHF, a model of moderate, stable, compensated heart failure. Overall, the cardioprotective benefits of GLP-1 and AC3174 appeared similar, suggesting that in this model, the major GLP-1 metabolite (GLP-1 9-36) is not necessary for mediating these specific improvements. Therefore, based on the findings from the present study and the accumulating body of clinical evidence with exenatide, therapy with GLP-1 receptor agonists may represent a promising approach for the treatment of patients with $\mathrm{CHF}$ or cardiovascular disease associated with type 2 diabetes, supporting the need for further research in this field.

\section{Abbreviations}

A: late; CHF: chronic heart failure; CO: cardiac output; Cyt: cytosolic; dp/dt: first derivative of LV pressure over time; DPP-4: dipeptidyl-peptidase-4; E: early; EC: exercise capacity; EDD: end-diastolic dimension; EDP: end-diastolic pressure; EF: ejection fraction; EDV: end-diastolic; ESD: end-systolic 
dimension; ESV: end-systolic volume; GLP-1: glucagon-like peptide-1; GLUT: glucose transporter; HOMA: homeostasis model assessment; HR: heart rate; LA: left atrial or left atrium; LV: left ventricular or left ventricle; MI: myocardial infarction; PM: plasma membranes; QMR: quantitative magnetic resonance; SERCA2: sarcoplasmic reticulum Ca ${ }^{2+}$ ATPase; SP: systolic pressure; SV: stroke volume; $\mathrm{VO}_{2}$ : oxygen consumption; $\mathrm{VTI}$ : velocity time integral.

\section{Acknowledgements}

We thank Dr. Todd Coffey for statistical consultation, Dr. Yvette Peters for medical writing, Amy Bloom for technical assistance and Dr. Loretta Nielsen for expert review and medical writing assistance with this manuscript. This work was funded by Amylin Pharmaceuticals, Inc. San Diego, CA.

\section{Author details}

'Amylin Pharmaceuticals Inc., San Diego, CA, USA 92121. ${ }^{2}$ Isis Pharmaceuticals, Carlsbad CA, USA. ${ }^{3}$ Arena Pharmaceuticals, San Diego CA, USA.

\section{Authors' contributions}

QL helped conceive of the study, and participated in its design, analysis, interpretation, coordination and helped draft the manuscript. CA participated in the design and coordination of the study. $A B, C P$, and RF participated in the design and coordination of the study and helped carry out the in vivo studies and the in vitro assays. cell biology and histological studies. AB helped conceive of the study and participated in its design. DGP helped conceive of the study, participated in its design, analysis, interpretation and helped draft the manuscript. All authors read and approved the final manuscript.

\section{Competing interests}

All authors were employees and held stock in Amylin Pharmaceuticals, Inc. at the time these experiments were performed.

Received: 8 October 2010 Accepted: 16 November 2010 Published: 16 November 2010

\section{References}

1. Drucker DJ: Minireview: the glucagon-like peptides. Endocrinology 2001, 142:521-527.

2. Drucker DJ: The biology of incretin hormones. Cell Metab 2006, 3:153-165.

3. Nauck MA, Meier Jj: Glucagon-like peptide 1 and its derivatives in the treatment of diabetes. Regul Pept 2005, 128:135-148.

4. Fields AV, Patterson B, Karnik AA, Shannon RP: Glucagon-like peptide-1 and myocardial protection: more than glycemic control. Clin Cardiol 2009, 32:236-243.

5. Göke R, Fehmann HC, Linn T, Schmidt H, Krause M, Eng J, Göke B: Exendin-4 is a high potency agonist and truncated exendin-(9-39)amide an antagonist at the glucagon-like peptide 1-(7-36)-amide receptor of insulin-secreting beta-cells. J Biol Chem 1993, 268:19650-19655.

6. Nielsen LL, Young AA, Parkes DG: Pharmacology of exenatide (synthetic exendin-4): a potential therapeutic for improved glycemic control of type 2 diabetes. Regul Pept 2004, 117:77-88.

7. Hargrove DM, Kendall ES, Reynolds JM, Lwin AN, Herich JP, Smith PA, Gedulin BR, Flanagan SD, Jodka CM, Hoyt JA, McCowen KM, Parkes DG, Anderson CM: Biological activity of AC3174, a peptide analog of exendin-4. Regul Pept 2007, 141:113-119.

8. Hansen PA, Corbett JA: Incretin hormones and insulin sensitivity. Trends Endocrinol Metab 2005, 16:135-136.

9. Noyan-Ashraf MH, Momen MA, Ban K, Sadi AM, Zhou YQ, Riazi AM, Baggio LL, Henkelman RM, Husain M, Drucker DJ: GLP-1R agonist liraglutide activates cytoprotective pathways and improves outcomes after experimental myocardial infarction in mice. Diabetes 2009, 58:975-83.

10. Vila Petroff MG, Egan JM, Wang X, Sollott SJ: Glucagon-like peptide-1 increases CAMP but fails to augment contraction in adult rat cardiac myocytes. Circ Res 2001, 89:445-452.

11. Zander M, Madsbad S, Madsen JL, Holst JJ: Effect of 6-week course of glucagon-like peptide 1 on glycaemic control, insulin sensitivity, and beta-cell function in type 2 diabetes: a parallel-group study. Lancet 2002, 359:824-830.
12. Ingelsson E, Sundstrom J, Arnlov J, Zethelius B, Lind L: Insulin resistance and risk of congestive heart failure. JAMA 2005, 294:334-341.

13. Kemppainen J, Tsuchida H, Stolen K, Karlsson H, Bjornholm M, Heinonen OJ, Nuutila P, Krook A, Knuuti J, Zierath JR: Insulin signalling and resistance in patients with chronic heart failure. J Physiol 2003, 550:305-315.

14. Stanley WC, Recchia FA, Lopaschuk GD: Myocardial substrate metabolism in the normal and failing heart. Physiol Rev 2005, 85:1093-1129.

15. Taegtmeyer $\mathrm{H}$ : Cardiac metabolism as a target for the treatment of heart failure. Circulation 2004, 110:894-896.

16. Bose AK, Mocanu MM, Carr RD, Brand CL, Yellon DM: Glucagon-like peptide 1 can directly protect the heart against ischemia/reperfusion injury. Diabetes 2005, 54:146-151.

17. Bose AK, Mocanu MM, Carr RD, Yellon DM: Myocardial ischaemiareperfusion injury is attenuated by intact glucagon-like peptide-1 (GLP1 ) in the in vitro rat heart and may involve the p70s6K pathway. Cardiovasc Drugs Ther 2007, 21:253-256.

18. Sonne DP, Engstrom T, Treiman M: Protective effects of GLP-1 analogues exendin-4 and GLP-1(9-36) amide against ischemia-reperfusion injury in rat heart. Reg Pept 2008, 146:243-249.

19. Timmers L, Henriques JPS, de Kleijn DPV, DeVries JH, Kemperman $H$ Steendijk P, Verlaan CWJ, Kerver M, Piek JJ, Doevendans PA, Pasterkamp G, Hoefer IE: Exenatide reduces infarct size and improves cardiac function in a porcine model of ischemia and reperfusion injury. J Am Coll Cardiol 2009, 53:501-510.

20. Zhao T, Parikh P, Bhashyam S, Bolukoglu H, Poornima I, Shen Y, Shannon R: Direct effects of glucagon-like peptide-1 on myocardial contractility and glucose uptake in normal and postischemic isolated rat hearts. J Pharmacol Exp Ther 2006, 317:1106-1113.

21. Murthy SN, St Hilaire R, Casey DB, Badejo AM, McGee J, McNamara DB, Kadowitz PJ, Fonseca VA: The synthetic GLP-I receptor agonist, exenatide, reduces intimal hyperplasia in insulin resistant rats. Diab Vasc Dis Res 2010, 7:138-144.

22. Nikolaidis LA, Mankad S, Sokos GG, Miske G, Shah A, Elahi D, Shannon RP: Effects of glucagon-like peptide-1 in patients with acute myocardial infarction and left ventricular dysfunction after successful reperfusion. Circulation 2004, 109:962-965.

23. Sokos GG, Nikolaidis LA, Mankad S, Elahi D, Shannon RP: Glucagon-like peptide-1 infusion improves left ventricular ejection fraction and functional status in patients with chronic heart failure. J Cardiac Failure 2006, 12:694-699.

24. Thrainsdottir I, Malmberg K, Olsson A, Gutniak M, Ryden L: Initial experience with GLP-1 treatment on metabolic control and myocardial function in patients with type 2 diabetes mellitus and heart failure. Diab Vasc Dis Res 2004, 1:40-43.

25. Halbirk M, Nørrelund H, Møller N, Holst JJ, Schmitz O, Nielsen R, NielsenKudsk JE, Nielsen SS, Nielsen TT, Eiskjær H, Bøtker HE, Wiggers H: Cardiovascular and metabolic effects of 48-h glucagon-like peptide-1 infusion in compensated chronic patients with heart failure. Am J Physiol Heart Circ Physiol 2010, 298:H1096-H1102.

26. Selye H, Bajusz E, Grasso S, Mendell P: Simple techniques for the surgical occlusion of coronary vessels in the rat. Angiol 1960, 11:398-407.

27. dos Santos L, Mello AFS, Antonio EL, Tucci PJF: Determination of myocardial infarction size in rats by echocardiography and tetrazolium staining: correlation, agreements, and simplifications. Brazilian J Med Biol Res 2008, 41:199-201.

28. Parkes $D$, Jodka C, Smith $P$, Nayak $S$, Rinehart $L$, Gingerich $R$, Chen $K$, Young A: Pharmacokinetic actions of exendin-4 in the rat: comparison with glucagon-like peptide-1. Drug Dev Res 2001, 53:260-267.

29. Yang X-P, Liu Y-H, Rhaleb N-E, Kurihara N, Kim HE, Carretero OA: Echocardiographic assessment of cardiac function in conscious and anesthetized mice. Am J Physiol Heart Circ Physiol 1999, 277:H1967-H1974.

30. Gottdiener JS, Bednarz J, Devereux R, Gardin J, Klein A, Manning WJ, Morehead A, Kitzman D, Oh J, Quinones M, Schiller NB, Stein JH, Weissman NJ: American Society of Echocardiography recommendations for use of echocardiography in clinical trials. J Am Soc Echocardiogr 2004, 17:1086-1119.

31. Litwin SE, Katz SE, Morgan JP, Douglas PS: Serial echocardiographic assessment of left ventricular geometry and function after large myocardial infarction in the rat. Circulation 1994, 89:345-354.

32. Kinugawa S, Wang Z, Kaminski PM, Wolin MS, Edwards JG, Kaley G, Hintze TH: Limited exercise capacity in heterozygous manganese 
superoxide dismutase gene-knockout mice: roles of superoxide anion and nitric oxide. Circulation 2005, 111:1480-1486.

33. Matthews DR, Hosker JP, Rudenski AS, Naylor BA, Treacher DF, Turner RC: Homeostasis model assessment: insulin resistance and beta-cell function from fasting plasma glucose and insulin concentrations in man. Diabetologia 1985, 28:412-419.

34. Tinsley FC, Taicher GZ, Heiman ML: Evaluation of a quantitative magnetic resonance method for mouse whole body composition analysis. Obes Res 2004, 12:150-160

35. Pfeffer MA, Pfeffer JM, Fishbein MC, Fletcher PJ, Spadaro J, Kloner RA, Braunwald E: Myocardial infarct size and ventricular function in rats. Circ Res 1979, 44:503-512.

36. Jonassen AK, Sack MN, Mjos OD, Yellon DM: Myocardial protection by insulin at reperfusion requires early administration and is mediated via Akt and p70s6 kinase cell-survival signaling. Circ Res 2001, 89:1191-1198.

37. Egert S, Nguyen N, Schwaiger M: Contribution of alpha-adrenergic and beta-adrenergic stimulation to ischemia-induced glucose transporter (GLUT) 4 and GLUT1 translocation in the isolated perfused rat heart. Circ Res 1999, 84:1407-1415.

38. Murray AJ, Lygate CA, Cole MA, Carr CA, Radda GK, Neubauer S, Clarke K: Insulin resistance, abnormal energy metabolism and increased ischemic damage in the chronically infarcted rat heart. Cardiovasc Res 2006, 71:149-157.

39. Erdogdua Ö, Nathansonb D, Sjöholmb Å, Nyströmb T, Zhang Q: Exendin-4 stimulates proliferation of human coronary artery endothelial cells through eNOS-, PKA- and PI3K/Akt-dependent pathways and requires GLP-1 receptor. Molec Cell Endocrinol 2010, 325:26-35.

40. Sauvé M, Ban K, Momen MA, Zhou Y, Henkelman RM, Mansoor Husain M, Drucker DJ: Genetic deletion or pharmacological inhibition of dipeptidyl peptidase-4 Improves cardiovascular outcomes after myocardial infarction in mice. Diabetes 2006, 59:1063-1073.

41. Panunti B, Kunhiraman B, Fonseca V: The impact of antidiabetic therapies on cardiovascular disease. Curr Atheroscler Rep 2005, 7:50-57.

42. Liao R, Jain M, Cui L, D'Agostino J, Aiello F, Luptak I, Ngoy S, Mortensen RM, Tian R: Cardiac-specific overexpression of GLUT1 prevents the development of heart failure attributable to pressure overload in mice. Circulation 2002, 106:2125-2131.

43. Gross R, You X, Baggio LL, Kabir MG, Sadi AM, Mungrue IN, Parker TG, Huang Q, Drucker DJ, Husain M: Cardiac function in mice lacking the glucagon-like peptide-1 receptor. Endocrinol 2003, 144:2242-2252.

44. Blonde L, Klein EJ, Han J, Zhang B, Mac SM, Poon TH, Taylor KL, Trautmann ME, Kim DD, Kendall DM: Interim analysis of the effects of exenatide treatment on $\mathrm{A} 1 \mathrm{C}$, weight and cardiovascular risk factors over 82 weeks in 314 overweight patients with type 2 diabetes. Diabetes Obes Metab 2006, 8:436-447.

45. Gedulin BR, Nikoulina SE, Smith PA, Gedulin G, Nielsen LL, Baron AD, Parkes DG, Young AA: Exenatide (exendin-4) improves insulin sensitivity and $ß$-cell mass in insulin-resistant obese fa/fa Zucker rats independent of glycemia and body weight. Endocrinol 2005, 146:2069-2076.

46. Mack CM, Moore CX, Jodka CM, Bhavsar S, Wilson JK, Hoyt JA, Roan JL, Vu C, Laugero KD, Parkes DG, Young AA: Antiobesity action of peripheral exenatide (exendin-4) in rodents: effects on food intake, body weight, metabolic status and side-effect measures. Int J Obes (Lond) 2006, 30:1332-1340.

47. Moretto TJ, Milton DR, Ridge TD, MacConell LA, Okerson T, Wolka AM, Brodows RG: Efficacy and tolerability of exenatide monotherapy over 24 weeks in antidiabetic drug-naive patients with type 2 diabetes: a randomized, double-blind, placebo-controlled, parallel-group study. Clin Ther 2008, 30:1448-1460.

48. Ossum A, van Deursa U, Engstrømb T, Jensenc JS, Treiman M: The cardioprotective and inotropic components of the postconditioning effects of GLP-1 and GLP-1(9-36)a in an isolated rat heart. Pharmacol Res 2006, 60:411-417.

49. Ban K, Noyan-Ashraf MH, Hoefer J, Bolz S, Drucker DJ, Husain M: Cardioprotective and vasodilatory actions of glucagon-like peptide 1 receptor are mediated through both glucagon-like peptide-1 receptor dependent and independent pathways. Circulation 2008, 117:2340-2350.

50. Kavianipour M, Ehlers MR, Malmberg K, Ronquist G, Ryden L, Wikstrom G, Gutniak M: Glucagon-like peptide-1 (7-36) amide prevents the accumulation of pyruvate and lactate in the ischemic and non-ischemic porcine myocardium. Peptides 2003, 24:569-578.
51. Nikolaidis LA, Elahi D, Hentosz T, Doverspike A, Huerbin R, Zourelias L, Stolarski C, Shen YT, Shannon RP: Recombinant glucagon-like peptide-1 increases myocardial glucose uptake and improves left ventricular performance in conscious dogs with pacing-induced dilated cardiomyopathy. Circulation 2004, 110:955-961.

52. Okerson T, Yan P, Stonehouse A, Brodows R: Effects of exenatide on systolic blood pressure in subjects with type 2 diabetes. Amer J Hypertens 2010, 23:334-339.

53. Gill A, Hoogwerf BJ, Burger J, Bruce S, MacConell L, Yan P, Braun D, Giaconia J, Malone J: Effect of exenatide on heart rate and blood pressure in subjects with type 2 diabetes mellitus: a double-blind, placebo-controlled, randomized pilot study. Cardiovasc Diabetol 2010, 9:6.

54. Sullivan SD, Alfonso-Cristancho R, Conner C, Hammer M, Blonde L: Longterm outcomes in patients with type 2 diabetes receiving glimepiride combined with liraglutide or rosiglitazone. Cardiovasc Diabetol 2009, 8:12.

55. Swan JW, Anker SD, Walton C, Godsland IF, Clark AL, Leyva F, Stevenson JC, Coats AJ: Insulin resistance in chronic heart failure: relation to severity and etiology of heart failure. J Am Coll Cardiol 1997, 30:527-532.

56. Fragasso G, Palloshi A, Puccetti P, Silipigni C, Rossodivita A, Pala M, Calori G, Alfieri $\mathrm{O}$, Margonato $\mathrm{A}$ : A randomized clinical trial of trimetazidine, a partial free fatty acid oxidation inhibitor, in patients with heart failure. J Am Coll Cardiol 2006, 48:992-998.

57. Lee L, Campbell R, Scheuermann-Freestone M, Taylor R, Gunaruwan $P$, Williams L, Ashrafian H, Horowitz J, Fraser AG, Clarke K, Frenneaux M: Metabolic modulation with perhexiline in chronic heart failure: a randomized, controlled trial of short-term use of a novel treatment. Circulation 2005, 112:3280-3288.

58. Ludvik B, Mayer G, Stifter S, Putz D, Barnas U, Graf H: Effects of dichloroacetate on exercise performance in healthy volunteers. Pflugers Arch 1993, 423:251-254

59. Gardiner S, March J, Kemp P, Bennett T: Mesenteric vasoconstriction and hindquarters vasodilatation accompany the pressor actions of exendin-4 in conscious rats. J Pharmacol Exp Ther 2006, 316:852-859.

60. Liu Q, Adams L, Broyde A, Fernandez R, Baron AD, Parkes DG: The exenatide analogue $A C 3174$ attenuates hypertension, insulin resistance, and renal dysfunction in Dahl salt-sensitive rats. Cardiovasc Diabetol 2010, 9:32.

61. Yu M, Moreno C, Hoagland KM, Dahly A, Ditter K, Mistry M, Roman RJ: Antihypertensive effect of glucagon-like peptide 1 in Dahl salt-sensitive rats. $J$ Hypertens 2003, 21:1125-1135.

62. Patel C, Wyne KL, McGuire DK: Thiazolidinediones, peripheral oedema and congestive heart failure: what is the evidence? Diab Vasc Dis Res 2005 2:61-66.

63. Lygate CA, Hulbert K, Monfared M, Cole MA, Clarke K, Neubauer S: The PPARgamma-activator rosiglitazone does not alter remodeling but increases mortality in rats post-myocardial infarction. Cardiovasc Res 2003, 58:632-7.

64. Watson RT, Pessin JE: GLUT4 translocation: the last 200 nanometers. Cell Signal 2007, 19:2209-2217.

65. Baggio LL, Huang Q, Brown TJ, Drucker DJ: Oxyntomodulin and glucagonlike peptide-1 differentially regulate murine food intake and energy expenditure. Gastroenterol 2004, 127:546-558.

66. Ban K, Kim K, Cho C, Sauvé M, Diamandis EP, Backx PH, Drucker DJ, Husain M: Glucagon-like peptide (GLP)-1(9-36)amide-mediated cytoprotection is blocked by exendin(9-39) yet does not require the known GLP-1 receptor. Endocrinol 2010, 151:1520-1531.

doi:10.1186/1475-2840-9-76

Cite this article as: Liu et al:: Glucagon-like peptide- 1 and the exenatide analogue AC3174 improve cardiac function, cardiac remodeling, and survival in rats with chronic heart failure. Cardiovascular Diabetology 2010 9:76. 